\title{
The (performance) management of retirement and the limits of individual choice
}

\begin{abstract}
The removal of the default retirement age in the UK has been broadly welcomed as the disposal of an age-discriminatory measure. It is argued here that a focus on formal equality has been at the expense of a more critical analysis of the employment relations consequences. The central role given to performance measurement allows employers considerable discretion over when employees retire and the scope for bargained outcomes in the new regime is limited. This may be to the detriment of older workers and will have implications for the workforce as a whole. Equality, in other words, may come at the expense of a broader conception of fairness.
\end{abstract}

Keywords: default retirement; employment relations; equality legislation; older workers

\section{Introduction}

Labour market predictions in the UK suggest that the role of older workers will become more important as numbers within younger cohorts decrease. This is not a straightforward consequence of changing demographics, but has resulted from a number of related policy developments whose aim has been the increased integration of older workers (Dini, 2009). Current policy, developed at a time of 
labour market tightening, treats older workers as an 'untapped resource' (DWP, 2013). This process began with the Employment Equality (Age) Regulations 2006 and, by 2010, the UK was among the countries that met the European Union goal of a 50\% employment rate among workers aged 55-64. One consequence of the 20082009 recession across Europe was a move away from encouraging early retirement and towards 'downshifting', that is the reduction of working time and introduction of gradual or phased retirement (Eurofound, 2012). In 2011, the abolition of the UK default retirement age (DRA) effectively removed arbitrary upper age limits on employment and has been broadly welcomed, both as a solution to a forecast fiscal problem and as a socially progressive move that underscores individual rights.

It is generally the case that the starting point for academic analysis has been an acceptance of both the economic and moral case for extending working lives. There is now an extensive literature on older workers in the labour market and on factors influencing retirement decisions (see inter alia White, 2012, and special issues of Social Policy and Society 2013, vol. 12, No. 1 and Employee Relations, 2013, vol. 35, No. 3). Much of the literature on this topic construes the ability to work longer as a matter of age equality. The decision to continue working is assumed to be, to a large extent, an individual one. In this regard, there is a positive story to be told. The specific cases of 'good practice' companies such as B\&Q or BT and their highly capable older workers who are working beyond what used to be retirement age are well known. There are, of course, also persistent social and economic constraints on individual choice (Loretto and Vickerstaff, 2013), and neither the willingness nor 
the ability to continue working can be taken for granted (Vickerstaff, 2010). The assumption is, nevertheless, that the removal of the main institutional mechanism of discrimination is a significant move in promoting the positive freedom to continue work.

It is argued here that this is only one side of the story. A focus on formal equality has led to a neglect of the processes by which retirement decisions are made. Outcomes are necessarily mediated by workplace relations and no meaningful evaluation of the new regulations is possible without understanding how these play out at this level. Research to date has largely neglected the organisational context of individual decisions as arising from broader management and employment relations' processes (useful exceptions are Fuertes et al, 2013; Templer and ArmstrongStrassen, 2008). Labour market analysis tends to focus on workers in the aggregate (cf. Roberts, 2006), while those writing from an equalities perspective focus on the right, or the ability, to continue in employment (compare Verbeek, 2011). This discussion has often been at a level of abstraction that does not acknowledge that the chief constraint on choice is the nature of the employment relationship (Loretto and Vickerstaff, 2013). In fact, it is difficult to evaluate de facto rights without acknowledging that this relationship is inherently asymmetric and messy.

Where the needs and preferences of older employees and their employers do not tally, there is potential for conflict, because the removal of the DRA simultaneously introduced the hope - or requirement - of extended working for the former, while 
seeming to limit the latter's ability to control when workers leave. For older workers who want, or need, to remain in employment, but who do not have the capabilities that the employer requires, options are limited (Vickerstaff, 2010). Specifically, low paid workers have limited access to an occupational pension (ONS, 2012) and may also have worked in conditions that have taken a physical toll. In 2011 almost $60 \%$ of employers were concerned that older workers would not retire even when unable to perform their job effectively (LCCI /Penningtons, 2011). Although emphasis has been placed on negotiation to overcome such situations, there are a number of far-reaching problems.

The following provides a brief outline of what the concept of retirement means following the abolition of the DRA and then explores possible implications. First, outcomes may be far from equal, since different groups of employees will have different abilities and bargaining power. Second, a focus on intergenerational equality - that is equality between older and younger workers at a particular moment - can be contrasted with a notion of fairness over the course of a working life (White, 2012, Roberts, 2006). White (2012) describes how managers may justify the easing of pressure on older workers as reward for long and loyal service. However, such apparently favourable treatment, although it may be widely regarded as 'fair', may now be considered discriminatory. Older workers stand to be judged on their weaknesses, not on their strengths. Third, in order to demonstrate equal treatment, employers are effectively compelled to implement forms of performance management (PM) that would otherwise be deemed unnecessary or 
counterproductive. The effects of these schemes go far beyond older workers themselves. In summary, while employees are now free from the need to retire on a fixed date, it is employers who are free to decide the criteria for continued employment.

\section{What does 'retirement' mean without a retirement age?}

The 2006 Employment Equality (Age) Regulations ended the voluntarist approach to age discrimination taken by successive UK governments. The regulations prohibited discrimination against employees on the grounds of age (Herring, 2011), except where this could be shown to be a "proportionate means of achieving a legitimate aim" (Sargeant, 2006: 220). The inclusion of a DRA meant that it remained possible for employers to dismiss employees once they turned 65, provided that this could be 'objectively justified' (Sargeant, 2006). Employees (including those over 65) were able to claim that their dismissal was unfair, but the burden of proof lay with them. Employees therefore gained the 'right to request', but not the positive right to continued employment. Paradoxically, therefore, a set of regulations designed to ensure equality explicitly allowed one of the most prevalent forms of age discrimination - enforced retirement. Where employers could justify a compulsory retirement age that was below the DRA of 65, employees might be forced to retire before becoming entitled to an alternative source of income (Kilpatrick, 2008). 
The Coalition post-election 'programme for government' phased out the DRA from October 2011. Except in certain cases (see below), 'retirement' on the grounds of age is now not an option. To dismiss a worker fairly, an employer will normally need to demonstrate that this is on grounds of capability or conduct. To the extent that employers previously saw retirement as the 'soft option', they are now obliged to develop more formal mechanisms. This has consequences for how older workers are managed and how they eventually end their working lives, raising issues not only of age equality, but also for more complex issues of fairness and dignity (Vickers and Manfredi, 2013).

Retirement means something quite different in the post-DRA era. The language of individual rights, which continues to be used to describe this change, suggests that workers may now decide when to 'retire'. "Most people can now work for as long as they want to" (Gov.uk, 2013). Not only is this highly misleading, but it also ignores the broader employment relations impact. In effect, the ending of the DRA shifts the balance of power between employees and employer. Workers with the greatest need or desire to continue working are not necessarily those whom the employer would choose to retain. For example, in the construction industry, relatively low pay and poor pension coverage, combined with high physical demands means that requests for extended work may come from those for whom it is least appropriate (Beck, 2013). It remains possible for an employer to set a compulsory retirement age if this can be 'objectively justified'. In the landmark case of Seldon v Clarkson Wright and Jakes (Vickers and Manfredi, 2013) a compulsory retirement age was 
defended on the grounds that the employer sought to limit the need to utilise PM to remove older workers. As shown below, this is in direct contrast with current guidance, which enhances the role of PM.

As was the case with reforms to tackle other forms of inequality, the abolition of the DRA is a product of its time and motivated by wider political and economic priorities. Most obviously, it arises during economic recession and at a time when the debate about the sustainability of public finances has been framed in terms of the demographics of the 'baby boom' generation (DWP, 2009). According to this analysis, with growing life expectancy, there is no alternative to increasing the labour market participation of older people. However, as there is a 'limited desire' to continue working (Vickerstaff et al., 2008) unless there is either a financial need or an intrinsic desire to work, the ending of the DRA alone might be expected to have only a marginal effect. Labour market projections anticipate a combined effect of ending the DRA and raising the state pension age (Wood et al., 2010), in other words, policy is reliant upon both choice and compulsion.

\section{Equality versus fairness}

In attempting to "reduce the number of older employees forced to retire against their will" (DWP, 2010: 26) the objective of the regulations is equal treatment between (loosely defined) generations. However, by definition, since this change is designed to equalise treatment, it has implications for all employees. It therefore needs to be assessed in terms of its wider effect, rather than simply as an anti- 
discrimination measure. In order to avoid an adverse impact on older or younger workers, employers will increasingly need a systematic and age-neutral approach to managing individual performance, as well as structured disciplinary/capability procedures. Employers will generally need to demonstrate that dismissal is for reasons related to capability or conduct. PM takes on a new significance as the obvious transparent and non-discriminatory mechanism to terminate employment. As early as 2011, The Age and Employment Network (TAEN) reported that almost a quarter of organisations had reviewed or changed their PM and capability appraisal procedures since the abolition of the DRA. In utilising PM, employers follow the explicit advice of the DWP (Müller-Carmen et al., 2011).

'If an employee is not delivering against their job role, you should address this through performance management, whatever their age.' (DWP, 2011a: 14)

This approach has met with a remarkable degree of consensus. Trade unions have often viewed PM techniques as divisive and exploitative (Taylor, 2013). Under the new regulations, by contrast, PM becomes the means to achieve equality and the negative consequences for individuals have therefore appeared secondary to the need for transparency and consistency.

'By failing to appraise older workers, employers aren't serving the best interests of the individual or the organisation.' (TUC/CIPD, 2007: 24) 
To the extent that unions have accepted the need for formal PM, this would seem to be at odds with the notion of fair treatment through the course of a working life that has been an unacknowledged expectation in employment relations. The focus of age discrimination legislation is thus on "enforcing equality rather than protecting older workers" (White, 2012: 451). Synchronous equality based on continual comparison has replaced an a-synchronous, or 'processional' approach in which "younger people eventually benefit from a provision which favours older employees" (Vickers and Manfredi, 2013: 66; Duncan, 2008). Equality now means being judged by the same criteria, so that older workers will "be treated more equally with those at earlier career stages, and will be required to perform more equally" (White, 2012: 451, emphasis in original). Synchronous equality is a considerable departure from how age groups have been managed to date. While $27 \%$ of employees reported not having had an appraisal in the last two years, for the over-65s the figure was $44 \%$. The CIPD see this "neglect" as the result of "lazy management" (CIPD, 2011a: 8).

Although it is now unlawful to single-out older workers, guidance suggests that 'informal' discussion about employees' 'options' may sit alongside formal disciplinary/capability procedures, thus blurring the boundary between the two and creating opportunities to use appraisal to 'suggest' retirement. Implicitly, this acknowledges that a threat of sanctions will be used to encourage employees to quit before dismissal becomes necessary. The DWP asserts that irrespective of possible social or financial restraints and compulsions, individuals "know when they are no 
longer able to carry on and self-select to leave or 'retire'" (DWP, 2011b: 4). However, there is also acknowledgement that employees' assessment of their options will be influenced by informal discussion. Rather than instinctively realising when it is time to leave, employees may now be told that they have no alternatives.

'Employers may wish to discuss with their older workers their options for working on and for retirement. Performance discussions provide the opportunity for that discussion to naturally arise.' (DWP, 2011a: 13)

To the question, “Isn't retiring someone more dignified than using performance management?", the DWP suggests, “There's nothing dignified about letting someone continue under-performing." (2011b: 8). The failure to tackle under-performance, it is suggested, may be deemed discriminatory if a younger worker would be treated differently. The alternative to persuading an underperforming employee to 'retire' is therefore to follow the same capability or disciplinary procedure that would apply to employees of any age. One supposed benefit of the change is that it will reduce the number of employment tribunal cases, and early evidence appears to support this view: tribunal cases peaked in 2010-11 (Ministry of Justice, 2012). Longer-term, however, a rigid adherence to a formal procedural approach may increase the use of sanctions, since HR managers become locked into a sequence of pre-defined stages.

'[E]mployers who may prefer to give an employee a 'good talking to' may be compelled to issue a formal warning in order to comply with a disciplinary 
procedure and ensure legal compliance' (Antcliff and Saundry, 2009: 112)

Early resort to formal sanctions is an existing tendency, particularly in small firms, where:

'... the move into the formal disciplinary procedure was regarded almost as reflecting a decision to dismiss, with the procedure being used either to stimulate a resignation or as an attempt to guard against the loss of a subsequent unfair dismissal claim.' (Goodman et al., 1998: 544/5).

The expansion of PM exacerbates this blurring of informal and formal. This is especially likely to happen in small firms who are important employers of older workers and also where the main growth of PM was expected (BIS, 2011). Although the majority of SMEs (95\%) claim to have formal PM systems in place that apply to 40 per cent or more of staff (Mitchie et al., 2008), it has already been noted that older workers are often excluded (CIPD, 2011a). Moreover, appraisals are usually administered by line managers, since small firms tend not to have access to specialist personnel/HR advice (ACAS, 2008). Not only does this make it difficult to separate performance management from informal discussion about retirement, but it also becomes difficult for individual employees to recognise the point at which representation, or accompaniment, becomes either necessary or allowable. 
Even when systematic PM is in place, results are not neutral, since the same procedure may be applied in different ways to different groups of workers. The tendency to experience the appraisal process as "low quality" appears to increase with age (Brown et al., 2010: 389). On the other hand, older workers - at least under the previous regulations - suffered fewer formal sanctions as a result of disciplinary action (Antcliff and Saundry, 2009). Although an age analysis of PM is yet to be developed, to date it seems that while employers have seen less need to resort to formal procedures in the final phase of working life, such measures may be seen as a prelude to retirement or dismissal. A differentiated treatment of older workers, which may be seen as an issue of fairness, is not possible in the new regime. Since PM systems are designed to discriminate between individual employees' levels of performance, even small age-related differences may enable employers to 'manage out' older-workers.

\section{Performance management and 'age neutrality'}

The emphasis in policy reform was on removal of barriers to participation in the labour market. The effectiveness of this approach relies upon age-neutral HR practices. However, the synchronous approach has quite different implications when applied to age, as compared with race, sex or disability, since it precludes consideration of the process of aging itself (Duncan, 2008: 1141). On the basis of an 'identity-blind' approach (Konrad and Linnehan, 1995), a suitably rigorous PM system is considered a sufficient defence against accusation of unlawful discrimination. Thus, the expected growth of formal appraisal and PM can be 
compared to the increased use of analytical job evaluation schemes by larger employers following the Equal Value amendment to the Equal Pay Act in 1983 (Gilbert, 2012). Although certain capabilities improve with experience, performance inevitably deteriorates at some point. Notwithstanding differences between types of work and the possibility of intelligently designed performance criteria, it remains the case that seemingly 'age-neutral' procedures based on the comparison of employees' performance may not result in the retention of older workers. On the contrary, it is possible that such an approach could result in workers being forced to leave employment at an earlier age than would have been the case with a fixed retirement age.

The HRM literature distinguishes between PM approaches based on absolute criteria and those that are explicitly comparative (Armstrong, 2012; Goffin et al., 2009), but by definition, all schemes that lead to some sort of rating become comparative. In other words, they are implicitly norm-referenced, in that employees are rated according to their relative performance. The same target or criterion may apply to all employees, but performance against that target will vary and the use of rewards or sanctions will depend on the overall distribution, rather than being based on individual performance in isolation. Individual managers are often reluctant to make such comparisons explicitly, leading some employers to introduce pre-set quotas for each performance level: 'forced distribution' systems. More generally, schemes that require managers to allocate workers to categories implicitly compare individual scores against the notional median, or 'satisfactory' 
employee (Armstrong, 2012). These schemes exist precisely in order to discriminate between different employees' performance levels. Particularly when they are attached to concrete outcomes, such schemes create competitive frameworks within an organisation's workforce and, in the case of functions or skills for which some age-related deterioration applies, older employees' rankings might be expected to reflect this. Irrespective of employers' views of older workers, the point is that these workers are not called upon to demonstrate that they can reach a fixed, acceptable performance standard. Instead, they need to be more capable, or productive, than at least some of their colleagues. The concept of 'underperformance' is, by definition, a relative one.

Having identified relative underperformance, employers need to identify whether improvement is possible. The requirement to make reasonable adjustments in the case of disability is well understood but if impairment is acquired with age the disabled label is not necessarily appropriate. In cases of age-related underperformance capabilities may change gradually, requiring regular monitoring and reassessment. To date, dismissal based on moveable performance thresholds as in the crude 'rank and yank' approach, could be considered unfair in the UK. The new status accorded to PM opens the possibility of dismissing 'older' workers quite legitimately even before their performance on the job is noticeably problematic by any 'absolute' criteria. 
There is no explicit requirement under the new regulations to adopt a formal system, but this is recommended as good practice (CIPD, 2011b). Official guidance is also silent on what constitutes an appropriate system. In reality, objectivity in the assessment of older workers is difficult to achieve. HR procedures do not exist in a vacuum and, however analytic a procedure may appear on paper, its practical application is inevitably affected by a range of other factors. For this reason, PM systems are always 'identity-conscious' (Konrad and Linnehan, 1995). At some stage, employers need to discuss the options available with their older employees. By definition, this involves the singling-out of individuals according to age and, depending upon individuals' performance and capabilities, employers will need to discuss 'retirement' as one option.

\section{Implications and lessons}

Employers' initial reaction to the ending of the DRA focused on the possibility of employees opting to remain beyond their usefulness, raising questions why they should retain older workers whose skills are not required. Employers who might have been prepared to let older workers 'wind down' before retirement now have the incentive and the means to force a 'perform or quit' decision. Employees are to be given the 'dignity' of knowing exactly how they fall short of expected standards and managers who would previously have seen pre-retirement workers as a special case are now compelled to put them in competition with younger colleagues. A perverse consequence is that employers may now encourage 'retirement' at an earlier age than previously. It is also possible that the 'older old' may be pitched 
against the 'younger old', further fragmenting the bargaining power of older workers as a constituency. These are important trade union concerns since they represent a shift in the frontier of control at work (Taylor, 2013).

More importantly, the regulations implicitly put all workers in competition with each other. The new status accorded to PM means that organisations that would otherwise have avoided formal schemes, seeing them as divisive, costly, or simply unnecessary, are now under pressure to adopt some objective means of justifying the way they treat workers of different ages. There are often financial reasons to replace older with younger workers. The new status of PM as the benchmark of equality strengthens this incentive by making comparison between age groups inevitable. Older workers' strengths may more than compensate for weaknesses, but PM is not open to this sort of evaluation. Employers retain considerable discretion in how performance appraisals are utilised and this has clear implications for employees and their unions. Union endorsement, or at least acceptance of performance management reflects a far less nuanced understanding of equality than has been the case with, say, disability. The prospect of older workers being thrown into intensified competition with younger colleagues is at odds with long-standing concepts of age-fairness, which have been based on recognition of different needs. Arguably, continuing union influence may require a more detailed assessment of the mechanics of PM, as well as a reappraisal of how different age 'constituencies' are represented. 
There are also lessons for the understanding of equality. Much of the impetus behind recent changes to age-related regulations relied on the interpretation of the regulations as a positive move towards equality. Whereas analysis in other areas of equality has evolved through argument and through struggle over time, developments in age-equality have been rapid and conducted without reference to a coherent, identifiable constituency of older workers. Age equality is 'about' everyone and so it has been possible to assume consensus, meaning that the debate has been conducted within largely depoliticised terms of reference. In particular, analyses have tended to avoid the issue of power and therefore rest on a surprisingly naïve conception of individual choice. Retirement therefore needs to be framed as an employment relations issue. This, in turn, calls for the reproblematising of performance management, since, as Taylor points out (2013), a lack of critical engagement has allowed a unitarist HRM view of performance management to go almost unchallenged.

For policy makers, the test of the new regime is its impact on labour market participation. However, this aggregate picture says very little about the effect of policy on working life. Retirement decisions cannot be properly understood without refocusing research on the workplace context. How long and how hard an individual works are influenced by national policy, but determined locally. The extent to which this can be construed as individual choice must therefore be seen as an empirical question. 


\section{Bibliography}

ACAS (2008) Small firms and workplace disputes resolution, Working Paper 01/08, London: ACAS.

Antcliff V and Saundry R (2009) Accompaniment, workplace representation and disciplinary outcomes in British workplaces - Just a formality? British Journal of Industrial Relations 47(1): 100-121.

Armstrong M (2012) Armstrong's Handbook of Reward Management Practice: Improving Performance through Reward (4th Edition). London: Kogan Page.

Beck, V. (2013) Employers' use of older workers in the recession, Employee Relations, 35(3): 257-271.

BIS (2011) Phasing out the default retirement age: government response to consultation. Impact assessment. Available at: www.gov.uk/government/uploads/system/uploads/attachment_data/file/79304/ 11-634-phasing-out-default-retirement-age-impact-assessment.pdf.

Brown M, Hyatt D and Benson J (2010) Consequences of the performance appraisal experience. Personnel Review 39(3): 375-396. 
CIPD (2011a) Employee Outlook: Focus on managing an ageing workforce. London: Chartered Institute of Personnel and Development.

CIPD (2011b) Managing Age. London: Chartered Institute of Personnel and Development.

Dini E (2009) Older workers in the UK: variations in economic activity status by socio-demographic characteristics, household and caring commitments. ONS Population Trends 137: 11-24.

Duncan, C. (2008) The dangers and limitations of equality agendas as a means of tackling old-age prejudice. Ageing and Society 28(8): 1133-1158.

DWP (2009) Building a society for all ages. The Stationery Office, Cm. 7655.

DWP (2010) Phasing out the default retirement age, consultation document, DWP/BIS. London: Department for Work and Pensions.

DWP (2011a) Workforce management without a fixed retirement age. London: Department for Work and Pensions.

DWP (2011b) Answers to employers questions. London: Department for Work and Pensions. 
DWP (2013) Employing older workers. An employer's guide to today's multigenerational workforce. London: Department for Work and Pensions.

Eurofound (2012) Employment trends and policies for older workers in the recession. Available at: www.eurofound.europa.eu/pubdocs/2012/35/en/1/EF1235EN.pdf.

Fuertes V, Egdell, V and McQuaid, R (2013) Extending working lives: age management in SMEs. Employee Relations 35(3): 272-293.

Gilbert K (2012) Promises and practices: job evaluation and equal pay forty years on! Industrial Relations Journal 43(2): 137-151.

Goffin R, Jelley B, Powell D and Johnston, N (2009) Taking advantage of social comparisons in performance appraisal: the relative percentile method. Human Resource Management 48(2): 251-268.

Goodman J, Earnshaw J, Marchington M and Harrison R (1998) Unfair dismissal cases, disciplinary procedures, recruitment methods and management style: case studies from three industrial sectors. Employee Relations 20(6): 536-550.

Gov.uk (2013) Retirement age. Available at: www.gov.uk/retirement-age. 
Herring J (2011) Age Discrimination and the Law: Forgin the Way Ahead. In: Parry E and Tyson S (eds) Managing an Age Diverse Workforce. Basingstoke: Palgrave Macmillan, 24-39.

Kilpatrick C (2008) The new UK retirement regime, employment law and pensions. Industrial Law Journal 37(1): 1-24.

Konrad A and Linnehan F (1995) Formalized HRM structures: coordinating equal employment opportunity or concealing organizational practices? Academy of Management Journal 38(3): 787-820.

LCCI / Penningtons (2011) Tackling the age-old problem of retirement. London: London Chamber of Commerce and Industry and Penningtons Solicitors.

Loretto W and Vickerstaff S (2013) The domestic and gendered context of retirement. Human Relations 66(1): 65-86.

Ministry of Justice (2012) Employment Tribunals and EAT Statistics, 2011-2012. Available at: www.gov.uk/government/uploads/system/uploads/attachment_data/file/163468 /annual-tribunals-statistics-2010-11.pdf.pdf. 
Mitchie J, Zubanov N and Sheehan M (2008) Human resource management practices, organizational outcomes and performance: an analysis of WERS 2004 data. London: Department of Business, Enterprise and Regulatory Reform.

Müller-Carmen M, Flynn M and Schroeder H (2011) The impact of national context on managing age diversity: The cases of the UK and Germany. In: Parry E and Tyson S (eds) Managing an Age Diverse Workforce. Basingstoke: Palgrave Macmillan, 223245.

ONS (2012), Annual Survey of Hours and Earnings Pension Tables, 2012 Provisional Reuslts. Available at: www.ons.gov.uk/ons/publications/re-referencetables.html?edition=tcm\%3A77-294316.

Roberts I (2006) Taking age out of the workplace: putting older workers back in? Work, Employment and Society 20(1): 67-86.

Sargeant M (2006) The Employment Equality (Age) Regulations 2006: A Legitimisation of Age Discrimination in Employment. Industrial Law Journal 35(3): 209-227.

TAEN (2011) Survey finds most employers will let employees retire when they want. London: The Age and Employment Network. 
Taylor P (2013) Performance management and the new workplace tyranny: a report for the Scottish Trades Union Congress. Glasgow: STUC.

Templer A and Armstrong-Stassen M (2008) The HR management perspective on the elimination of mandatory retirement in Ontario. Relations Industrielles/Industrial Relations 63(4): 603-621.

TUC/CIPD (2007) Managing Age: A guide to good employment practice. London: Chartered Institute of Personnel and Development.

Verbeek S (2011) Employment equity policy frames in the literature: 'good practice' versus 'bad idea'. The International Journal of Human Resource Management 22(9): 1942-1962.

Vickers L and Manfredi S (2013) Age equality and retirement: Squaring the Circle. Industrial Law Journal 42(1): 61-74.

Vickerstaff S (2010) Older workers: The ‘Unavoidable Obligation' of extending our working lives. Sociology Compass 4(10): 869-879.

Vickerstaff S, Loretto W, Billings J, Brown P, Mitton L, Parkin T and White P (2008) Encouraging labour market activity among 60-64 year olds. Norwich: Research Report No 531 Department for Work and Pensions. 
White M (2012) Older employees under pressure? Theorizing reason for declining commitment. Work, Employment and Society 26(3): 447-463.

Wood A, Robertson $\mathrm{M}$ and Wintersgill D (2010) A comparative review of international approaches to mandatory retirement. Norwich: Research Report 674 Department of Work and Pensions. 


\section{Acknowledgements}

We would like to thank Rob MacKenzie and three anonymous reviewers for their helpful and constructive comments.

\section{Bibliographies}

Vanessa Beck is Lecturer in Employment Studies in the School of Management, University of Leicester.

Glynne Williams is Senior Lecturer in Industrial Relations in the School of Management, University of Leicester. 